\title{
Effects of Reaction Temperature on Microstruc- ture and Advanced Pseudocapacitor Properties of NiO Prepared via Simple Precipitation Method
}

\author{
Qiangqiang Sun, Shujuan Bao*
}

(Received 23 September 2013; accepted 28 October 2013; published online 15 November 2013)

\begin{abstract}
Morphology-controlled synthesis and large-scale self-assembly of nanoscale building blocks into complex nanoarchitectures is still a great challenge in nanoscience. In this work, various porous NiO nanostructures are obtained by a simple ammonia precipitation method and we find that the reaction temperature has a significant impact on their microstructures. Nanoflowers and nanoflakes have been obtained at $0^{\circ} \mathrm{C}$ and $50^{\circ} \mathrm{C}$, while, weakly self-assembly nanoflowers with nanoflakes are formed at $20^{\circ} \mathrm{C}$. In order to understand the process-structure-property relationship in nanomaterial synthesis and application, the as-prepared $\mathrm{NiO}$ is used as supercapacitor electrode materials, and evaluated by electrochemical measurement. The experimental results indicate that the material obtained at lower temperature has higher pseudocapacitance, the specific capacitance of 944,889 and $410 \mathrm{~F} / \mathrm{g}$ are reached for the materials prepared at $0^{\circ} \mathrm{C}, 20^{\circ} \mathrm{C}$ and $50^{\circ} \mathrm{C}$ and further calcined at $300^{\circ} \mathrm{C}$, respectively. While the material obtained at higher temperature has excellent rate capacity. This offers us an opportunity searching for exciting new properties of $\mathrm{NiO}$, and be useful for fabricating functional nanodevices.
\end{abstract}

Keywords: Nickel oxide; Temperature; Morphology; Pseudocapacitor

Citation: Qiangqiang Sun and Shujuan Bao, "Effects of Reaction Temperature on Microstructure and Advanced Pseudocapacitor Properties of NiO Prepared via Simple Precipitation Method", Nano-Micro Lett. 5(4), 289-295 (2013). http://dx.doi.org/10.5101/nml.v5i4.p289-295

\section{Introduction}

In recent years, nanomaterials, with different dimensionalities and morphologies attract much attention due to their novel and unexpected properties. Generally, size, dimensionality and morphology of the materials have been regarded as critical factors that may bring some unique or improved properties. For example, mesoporous structured nanomaterials enable rapid diffusion across a large surface area, which result in reduced response time and enhanced interaction with the environment [1]. Hence, numerous studies have accordingly been carried out in an effort to exploit cost-effective method to synthesis nanostructured oxides with controllable shapes, composition, and pores in order to modify or promote their intrinsic properties. Nickel oxide is a kind of very attractive inorganic material due to its high capacity, natural abundance, low cost, and environmental friendliness. Morphologycontrollable synthesis of $\mathrm{NiO}$ nanostructures has therefore a hot research topic for designing $\mathrm{NiO}$ nanomaterials with tunable properties.

Until now $\mathrm{NiO}$ with various morphologies, such as nanoparticles [2], nanoplates [3], nanotubes [4], nanowires [5], nanoribbons [6], hollow octahedral [7], nanowall [8], concave polyhedrons [9] and complex hierarchical nanostructures constructed with nanoscale building blocks [10] have been fabricated. And many different methods have been improved to synthesize the nanostructured $\mathrm{NiO}$, such as chemical precipita- 
tion [11], sol-gel method [12], microemulsion technique [13], solvothermal methods [14,15], and so on. Among these synthetic approaches, the ammonia precipitation method is promising because of inexpensive raw material and simple processing. The researchers also found that the microstructure of $\mathrm{NiO}$ formed by ammonia precipitation can be tailored by reaction condition. For example, Deng [16] has prepared uniform nanocrystalline $\mathrm{NiO}$ particles which had cubic shapes with weak agglomerate. And Lang [17] has synthesized $\mathrm{NiO}$ with nano-flake structure. But there is no report on the influence of reaction temperature on the microstructure of products in precipitation reaction.

In this work, we have carefully investigated the influence of reaction temperature on the microstructure of products formed in ammonia precipitation and given a rational proposal about their forming mechanism. Importantly, it's first time to perform this reaction at $0^{\circ} \mathrm{C}$. We dropped $5 \%$ aqueous ammonia to $1 \mathrm{M}$ nickel nitrate in different temperature to form $\mathrm{Ni}(\mathrm{OH})_{2}$. And after annealing at $300^{\circ} \mathrm{C}$ for $3 \mathrm{~h}$ in air, we could get nickel oxides which have very different microstructure. The as-synthesized samples were characterized by Xray diffraction (XRD), field emission scanning electron microscopy (FESEM), transmission electron microscopy (TEM) and nitrogen adsorption/desorption experiment for their microstructure and morphology. In order to investigate the effect of microstructure on performance, the as-prepared materials were used as electrochemical capacitor electrode materials, and some electrochemical techniques such as cyclic voltamogramm (CV) and electrochemical impedance spectroscopy (EIS) measurements were used to systematically study their microstructure-property relationship. The results indicate that the sample synthesized at $0^{\circ} \mathrm{C}$ and further annealed at $300^{\circ} \mathrm{C}$ although has a highest specific capacitance of $944 \mathrm{~F} / \mathrm{g}$ at the current density of $1 \mathrm{~A} / \mathrm{g}$, its rate capacity is worse, which is closely related with its textural properties. It demonstrates that the reaction temperature has a big impact on the crystallinity, microstructure and performance of materials, which provide a new way for preparation advanced materials with high performance.

\section{Experimental}

\section{Synthesis of $\mathrm{NiO}$}

Nickel nitrate hexahydrate was dissolved in deionized water $(\mathrm{Ni}$ concentration $=1.0 \mathrm{M})$ in a glass breaker under magnetic stirring. The nickel nitrate solution was slowly adjusted to $\mathrm{pH}=9$ by dropping additional $5 \mathrm{wt} \%$ aqueous $\mathrm{NH}_{3}$ for $2 \mathrm{~h}$ at the temperature of $0^{\circ} \mathrm{C}, 20^{\circ} \mathrm{C}$ and $50^{\circ} \mathrm{C}$, respectively. The resulting suspension was stirred at their temperature for another $2 \mathrm{~h}$. Then the solid was filtered off, washed with a copious amount of deionized water. After that, they were dried at $60^{\circ} \mathrm{C}$ for $4 \mathrm{~h}$ in air, and then were annealed at $300^{\circ} \mathrm{C}$ for 3 h.

\section{Characterizationas and electrochemical tests}

The crystal structure of the materials was characterized by powder XRD (XRD-7000). Morphology and microstructure of the synthesized materials were investigated by FESEM (S-4800, Japan) and TEM (JEM2100). Nitrogen adsorption/desorption was carried out at $77.3 \mathrm{~K}$ by means of an ASAP $2020 \mathrm{X}$ tended Pressure Sorption Analyzer. The surface area was calculated by using the Brunauer-Emmett-Teller (BET) equation. The pore size distribution (pore diameter, pore volume, and micropore surface area of the samples) was determined by the Barrett-Joyner-Halenda (BJH) method. And their hydrophilicity was evaluated by measuring contact angel (JC2000D1).

The electrodes of the electrochemical capacitors were fabricated by mixing the prepared powder with $15 \mathrm{wt} \%$ acetylene black and $5 \mathrm{wt} \%$ polytetrafluorene-ethylene binder of the total electrode mass. A small amount of alcohol was added to the mixture for a more homogeneous paste. The mixture was pressed onto nickel foam current collectors $\left(1.0 \times 1.0 \mathrm{~cm}^{2}\right)$ to make electrodes and the electrodes were dried at $80^{\circ} \mathrm{C}$ for $16 \mathrm{~h}$. Each electrode contains the active material in an area density of approximately $5.0 \mathrm{mg} / \mathrm{cm}^{2}$. Electrochemical characterization was carried out in a conventional three-electrode cell in $6 \mathrm{M}$ aqueous $\mathrm{KOH}$ electrolytes. Platinum foil and saturated calomel electrode (SCE) electrodes were used as the counter and reference electrodes, respectively. All electrochemical measurements were conducted using a CHI 660 electrochemical workstation (Shanghai Chenhua Co. Ltd., China).

\section{Results and discussion}

The XRD patterns of the $\mathrm{Ni}(\mathrm{OH})_{2}$ precursor are shown in Fig. 1(A). It shows that the crystallinity of precursor increase with the reaction temperature going up. The pattern $\mathrm{a}$ and $\mathrm{b}$ corresponds to a layered $\alpha-\mathrm{Ni}(\mathrm{OH})_{2}$ structure with low crystallinity. For the precursor obtained at $50^{\circ} \mathrm{C}$ (pattern c) displays three strong peaks, and all the diffraction peaks ascribe to well-crystallized $\beta$-phase hexagonal nickel hydroxide (JCPDS card, no.14-0117). The XRD patterns of samples formed by annealing the precursors at $300^{\circ} \mathrm{C}$ for $3 \mathrm{~h}$ are shown in Fig. 1(B). And the diffraction peaks are in good agreement with the standard XRD pattern of the pure cubic phase of $\mathrm{NiO}$ (JCPDS card, no.73-1523) indicating that the pure phase of $\mathrm{NiO}$ is obtained by calcining $\mathrm{Ni}(\mathrm{OH})_{2}$ precursor. Judging from the peaks intensity, after same sintering process, the sample which from the precursor obtained at $50^{\circ} \mathrm{C}$ has 
best crystallinity.

The surface morphology of the nanostructured $\mathrm{NiO}$ has been investigated using FESEM and TEM. It is clearly that the $\mathrm{NiO}$ obtained from different precursors exhibt different morphology (Fig. 2). The one which precursor obtained at $0^{\circ} \mathrm{C}$ is very slack $3 \mathrm{D}$ flower-like microsphere in the SEM image, and the nanostructure of single flower-like microspheres consisting of many intercrossed thin nanoflakelets. While the sample which precursor formed at $20^{\circ} \mathrm{C}$ is consist of some microspheres and some unequal-sized flakes. And the $\mathrm{NiO}$ which precursor obtained at $50^{\circ} \mathrm{C}$ consists of uniform large flakes. The higher magnifications TEM further reveal the morphologies of the $\mathrm{NiO}$ whose precursors were formed at different temperature. And the results

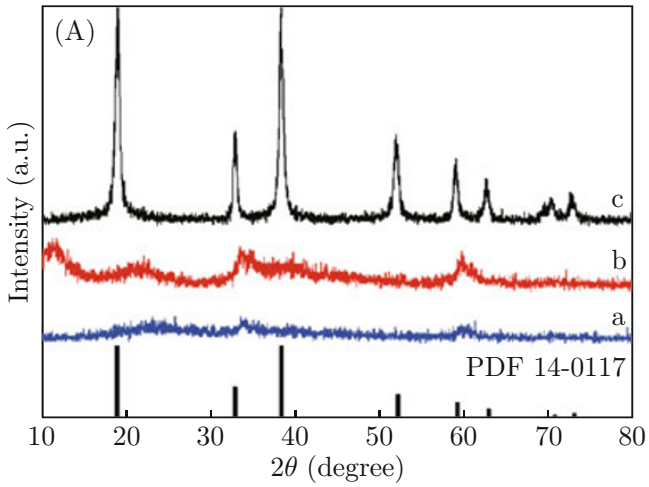

observed from TEM images are in agreement with that measured from SEM images.

The microstructure of the resultant $\mathrm{NiO}$ was further investigated by nitrogen adsorption-desorption experiments, as shown in Fig. 3. The nitrogen adsorptiondesorption isotherms of the $\mathrm{NiO}$ obtained by different precursors all exhibited hysteresis loops of type IV curves, indicating the mesoporous characteristics of the obtained samples. According to BET analysis, the specific surface area of $\mathrm{NiO}$ sample whose precursor formed at $0^{\circ} \mathrm{C}, 20^{\circ} \mathrm{C}$ and $50^{\circ} \mathrm{C}$ is $135 \mathrm{~m}^{2} / \mathrm{g}, 88 \mathrm{~m}^{2} / \mathrm{g}$ and 42 $\mathrm{m}^{2} / \mathrm{g}$, respectively. What's more, the samples all have a mesopore size distribution. And the pores may come from the porous nanoflowers, the gap between particles or thick slices.

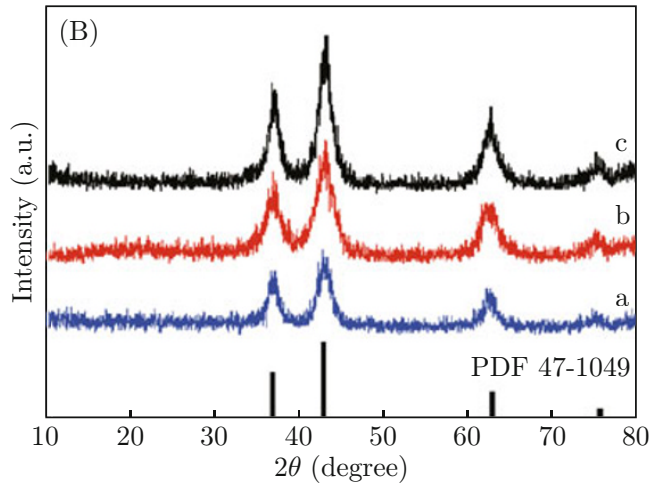

Fig. 1 The XRD patterns of $(\mathrm{A})$ the $\mathrm{Ni}(\mathrm{OH})_{2}$ precursor formed at (a) $0^{\circ} \mathrm{C}$; (b) $20^{\circ} \mathrm{C}$; (c) $50^{\circ} \mathrm{C}$ and (B) the $\mathrm{NiO}$ obtained by annealed the precursors of (a) $0^{\circ} \mathrm{C}$; (b) $20^{\circ} \mathrm{C}$; (c) $50^{\circ} \mathrm{C}$ at $300^{\circ} \mathrm{C}$ for $3 \mathrm{~h}$.
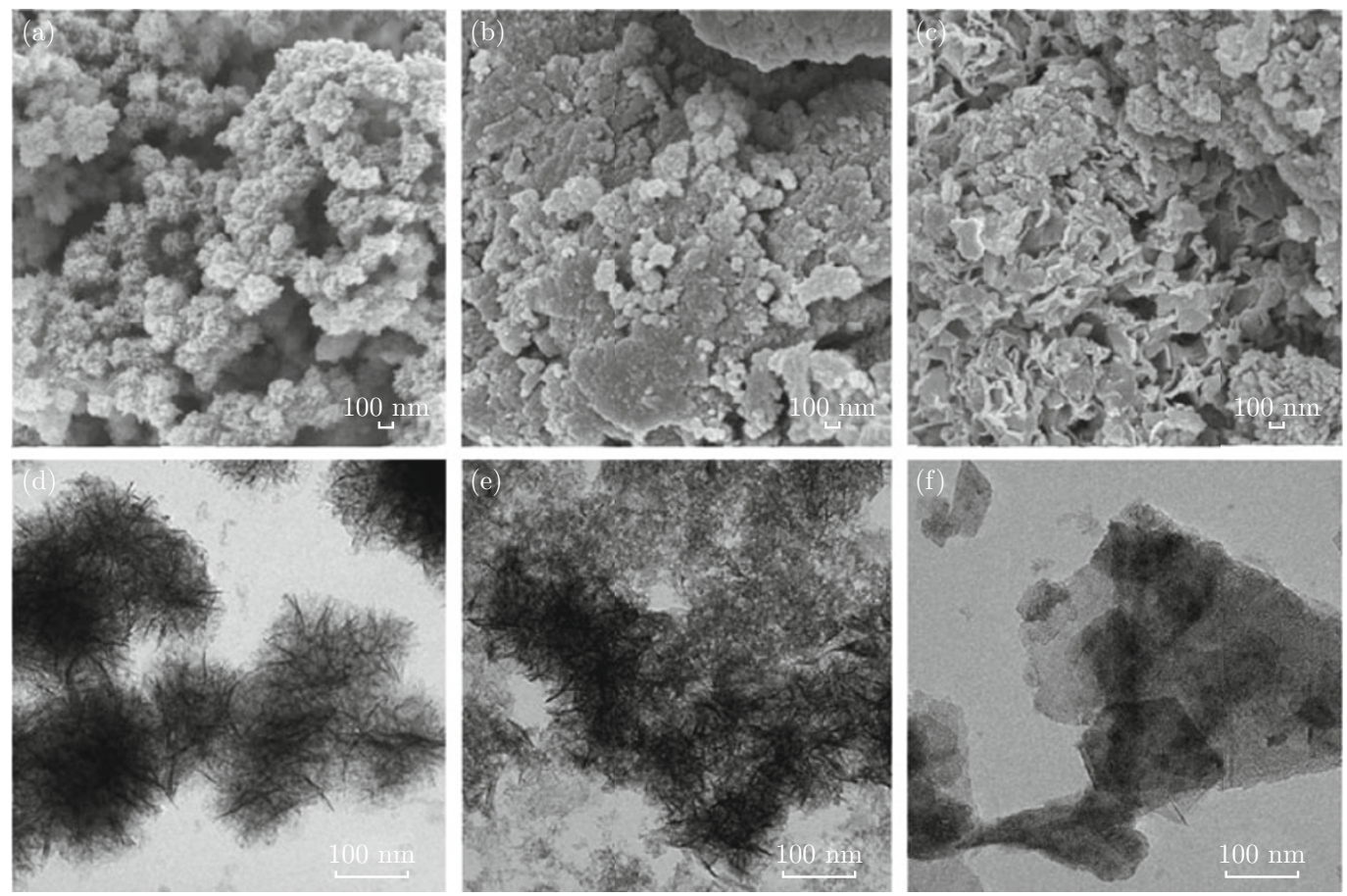

Fig. 2 SEM images (a, b, c) and TEM images (d, e, f) of $\mathrm{NiO}$ whose precursors were made at $0^{\circ} \mathrm{C}(\mathrm{a}, \mathrm{d}), 20^{\circ} \mathrm{C}(\mathrm{b}, \mathrm{e})$ and $50^{\circ} \mathrm{C}(\mathrm{c}, \mathrm{f})$. 

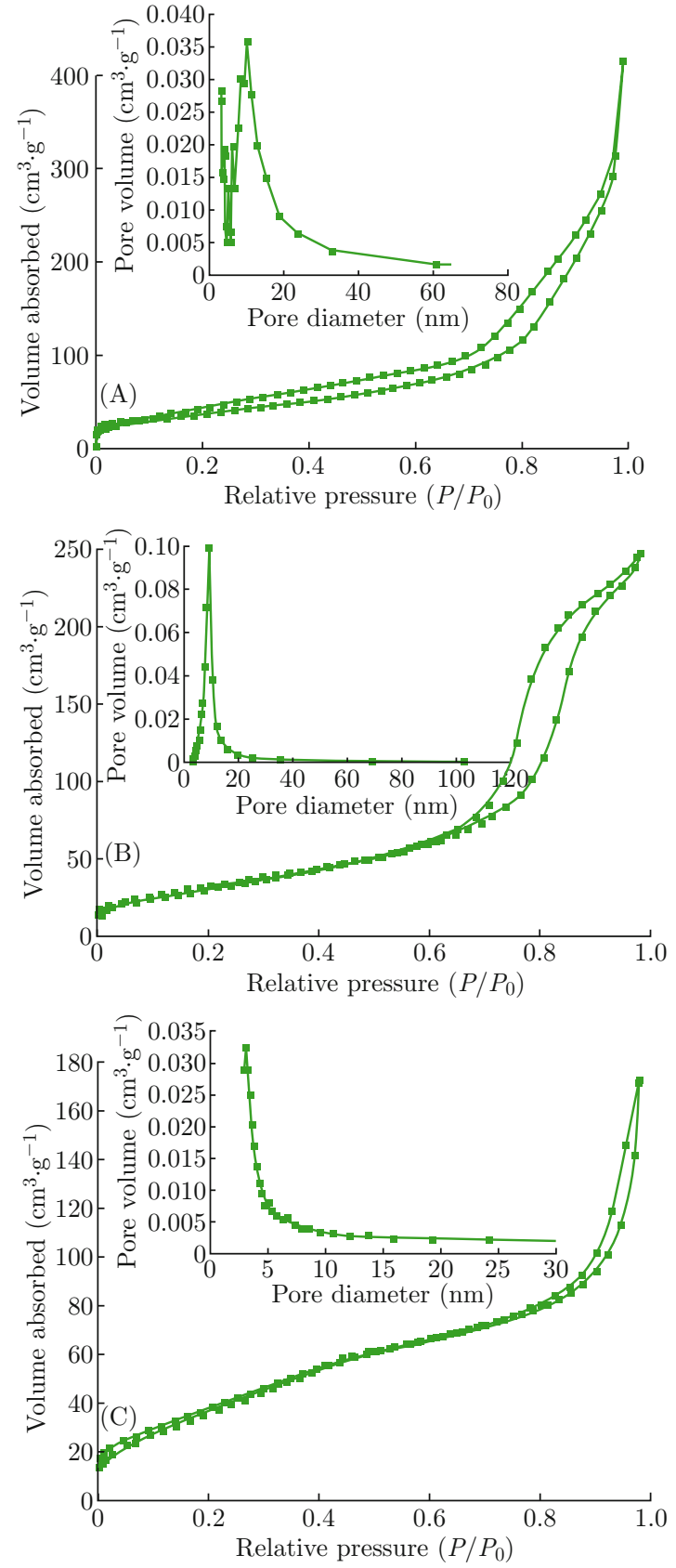

Fig. 3 BET isotherm of $\mathrm{NiO}$ whose precursors formed at (a) $0^{\circ} \mathrm{C}$; (b) $20^{\circ} \mathrm{C}$ and (c) $50^{\circ} \mathrm{C}$. The inset is $\mathrm{BJH}$ pore size distribution.

The hydrophilicity of the samples fabricated in this work was further evaluated by water contact angle measurements. The water contact angles of the $\mathrm{NiO}$ which precusor from $0^{\circ} \mathrm{C}, 20^{\circ} \mathrm{C}$ and $50^{\circ} \mathrm{C}$ are $30.43^{\circ}, 19.68^{\circ}$, $9.34^{\circ}$, respectively. Namely, after same sintering process, which precursor from higher temperature has excellent hydrophilicity. This result indicates that the reaction temperature has significant impact on the microstructures and crystallinity of the obtained materials, and further impacts their hydrophilicity.

It is very important to fully understanding the form- ing mechanism of crystal growth in our reaction system for realizing the precise controlled synthesis of various defined nanostructure. On the basis of above experimental results, the possible growth process of different structures can be proposed and described as Fig. 4. In the reaction of forming $\mathrm{Ni}(\mathrm{OH})_{2}, \mathrm{Ni}^{2+}$ ions in the solution are coordinated with $\mathrm{NH}_{3} \cdot \mathrm{H}_{2} \mathrm{O}$ to form $\left[\mathrm{Ni}\left(\mathrm{NH}_{3}\right)_{x}\right]^{2+}$ according to formula (1). The $\mathrm{OH}^{-}$concentration is increased as the ammonia hydroxide solution is introduced into the solution, as shown in formula (2). Due to the increasing of $\mathrm{OH}^{-}$concentration, the complex $\left[\mathrm{Ni}\left(\mathrm{NH}_{3}\right)_{x}\right]^{2+}$ are hydrolyzed into $\left[\mathrm{Ni}(\mathrm{OH})_{x}\right]^{(x-2)-}$, as shown in formula (3). Then, $\left[\mathrm{Ni}(\mathrm{OH})_{x}\right]^{(x-2)-}$ are dehydrated into $\mathrm{Ni}(\mathrm{OH})_{2}$ precipitates.

$$
\begin{aligned}
& \mathrm{Ni}^{2+}+x \mathrm{NH}_{3} \cdot \mathrm{H}_{2} \mathrm{O} \rightleftharpoons\left[\mathrm{Ni}\left(\mathrm{NH}_{3}\right)_{\mathrm{X}}\right]^{2+}+x \mathrm{H}_{2} \mathrm{O} \\
& \mathrm{NH}_{3} \cdot \mathrm{H}_{2} \mathrm{O} \rightleftharpoons \mathrm{NH}^{4+}+\mathrm{OH}^{-} \\
& {\left[\mathrm{Ni}\left(\mathrm{NH}_{3}\right)_{3}\right]^{2+}+x \mathrm{OH}^{-} \rightleftharpoons\left[\mathrm{Ni}(\mathrm{OH})_{\mathrm{X}}\right]^{(\mathrm{X}-2)-}+x \mathrm{NH}_{3}}
\end{aligned}
$$

Figure 4 shows the schematic illustration of the major reactions involved in the synthesis process at different temperature. In the initial stage of the reaction, $\left[\mathrm{Ni}\left(\mathrm{NH}_{3}\right)_{\mathrm{y}}\right]^{2+}$ are hydrolyzed to form $\mathrm{Ni}(\mathrm{OH})_{2} \mathrm{nu}-$ clei. With the reaction going on, the primary $\mathrm{Ni}(\mathrm{OH})_{2}$ nuclei change into $\mathrm{Ni}(\mathrm{OH})_{2}$ nanoflakelets through a subsequent crystal growth process. At the same time, each nanoflakelets have their own orientated growth process. These grown progresses are related to both the anisotropic crystal structure of $\mathrm{Ni}(\mathrm{OH})_{2}$ and the involved solution conditions. At $0^{\circ} \mathrm{C}, \mathrm{Ni}(\mathrm{OH})_{2}$ nanoflakelets grow very slowly, and from the thermodynamics point of view, the surface energy of the new formed nanoflakelets is quite high with two main exposed planes, and thus the neighboring nanosheets tended to grow toghther form $3 \mathrm{D} \mathrm{Ni}(\mathrm{OH})_{2}$ flower-like microspheres by self-assembled [18]. As reported in literatures, the direct reason for self-assembly is crystalface attraction, van der waals forces and hydrogen bonds $[19,20]$. For the reaction at $20^{\circ} \mathrm{C}$, the reaction speed is faster than that of at $0^{\circ} \mathrm{C}$, so it can produce much more primary particles, and much more nanoparticles are easy to form thicker nanaoflakelets with the crystal growth, due to its surface energy is lower the one got at $0^{\circ} \mathrm{C}$, only part of the nanoflakelets self-assembled into nanoflowers. As for the situation at $50^{\circ} \mathrm{C}$, the mechanism is similar to the first two, and the difference is that the nanofakelets are too thick to self-assemble into nanoflowers.

Remission of environmental and energy crises in recent years have wide applications especially in energy storage. It is well known that $\mathrm{NiO}$ has high pseudocapacity, and the $\mathrm{NiO}$ obtained in our work has very slack porous structure, which not only could boost ion and electron fast movement in electrochemical processes but 


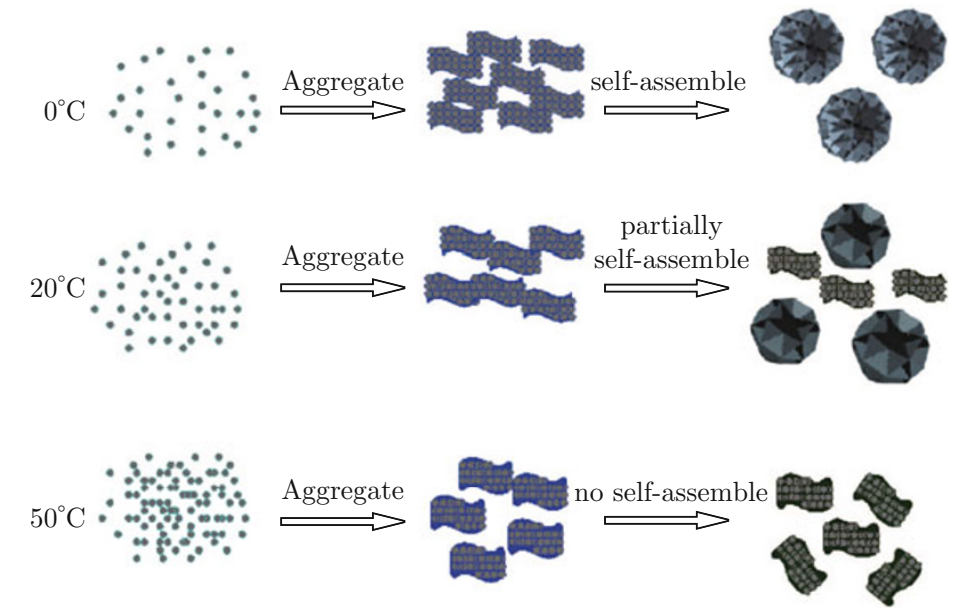

Fig. 4 Schematic illustration of the morphological evolution of the precursors formed at different temperature.
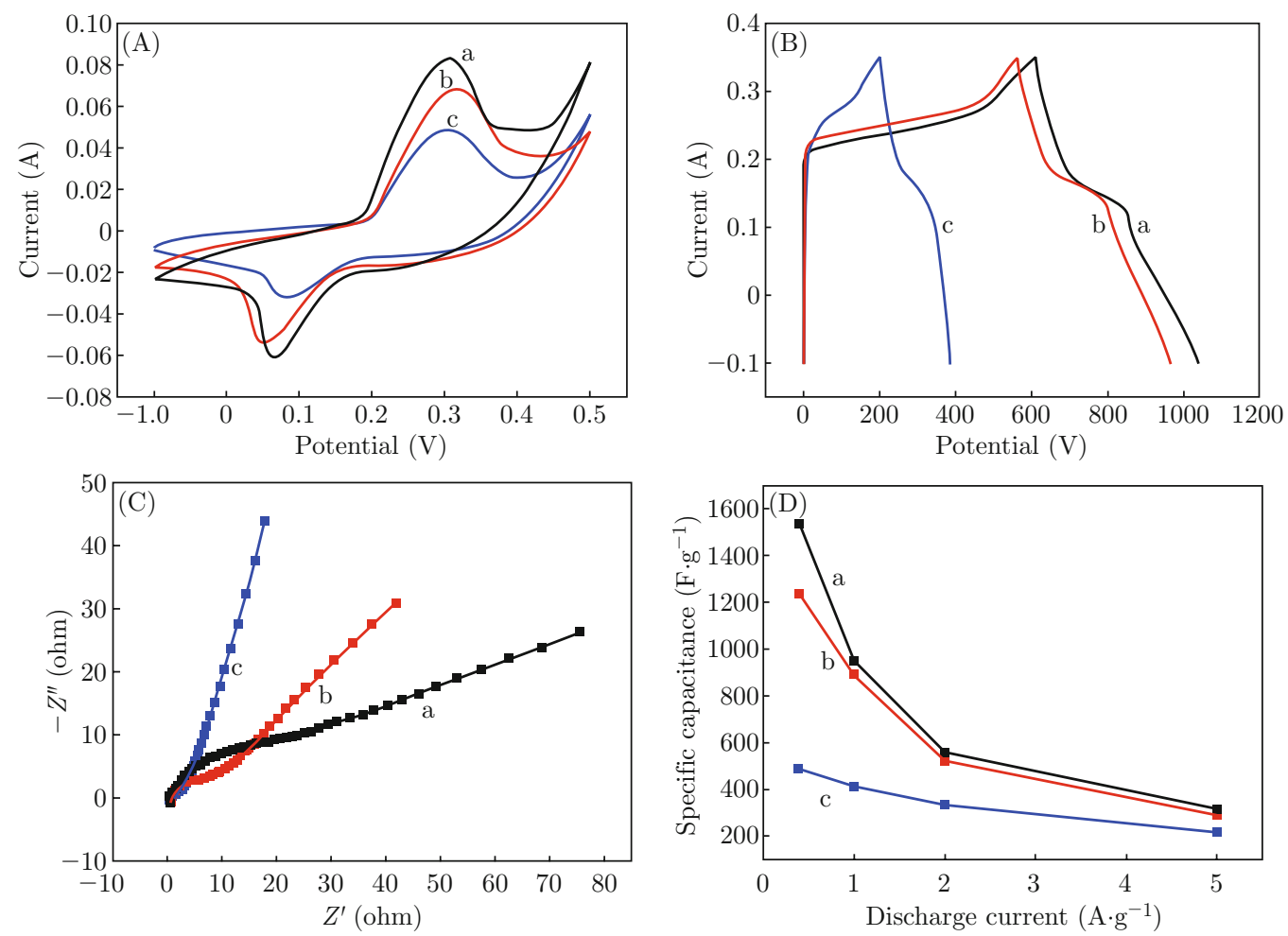

Fig. 5 (A) $\mathrm{CV}$ curves of $\mathrm{NiO}$ whose precursors was respectively synthesized at (a) $0^{\circ} \mathrm{C}$; (b) $20^{\circ} \mathrm{C}$; (c) $50^{\circ} \mathrm{C}$ at the scanning rate of $5 \mathrm{mV} / \mathrm{s}$. (B) Galvanostatic charge and discharge curves of $\mathrm{NiO}$ with a current density of $1 \mathrm{~A} / \mathrm{g}$. (C) Nyquist plots for $\mathrm{NiO}$ electrode at potential of $0.1 \mathrm{~V}$. (D) the capacitances under different discharge current.

also have big specific surface area. Hence, the assynthesized materials were used as electrochemical capacitor electrode materials to estimate the processstructure-property relationship of the obtained $\mathrm{NiO}$ in this work.

As shown in Fig. 5(A), all the as prepared $\mathrm{NiO}$ whose precursor obtained at different temperature show a pair of redox peaks in the CV curves, which due to the following reversible electrochemical reaction.

$$
\mathrm{NiO}+\mathrm{OH}^{-} \rightleftharpoons \mathrm{NiOOH}+\mathrm{e}^{-}
$$

Among of these CV curves, the area under the CV curve for $\mathrm{NiO}$ whose precursor obtained at $0^{\circ} \mathrm{C}$ is apparently larger than that of other samples, and the order of their area is $\mathrm{a}>\mathrm{b}>\mathrm{c}$, demonstrating that the $\mathrm{NiO}$ whose precursor formed at lower temperature has higher capacitance, possibly due to its more slack structure and larger specific surface area.

The charge-discharge performance measurements were further used to estimate the pseudocapacity properties of as-prepared materials. As shown in Fig. 5(B), during the charge and discharge steps, the curves dis- 
play two variation ranges. A perfect variation of potential vs. time (below about $0.1 \mathrm{~V}$ ) parallel to the potential axis indicates a pure double-layer capacitance behavior from the charge separation at the electrode/electrolyte interface, and a sloped variation of the potential vs. time $(0.1 \sim 0.35 \mathrm{~V})$ shows a typical pseudocapacitance behavior, caused by the electrochemical adsorption/adsorption or redox reaction at the electrode/electrolyte interface. The specific capacitance of the electrodes at a current density of $1 \mathrm{~A} / \mathrm{g}$ is calculated by $C=\frac{I \times \Delta t}{\Delta V \times m}$ from the discharge curves, where $I$ is the constant discharge current, $\Delta t$ is the discharge time, $\Delta V$ is the potential drop during discharge, and $m$ is the mass of $\mathrm{NiO}$. The specific capacitance value is 944, 889 and $410 \mathrm{~F} / \mathrm{g}$ were calculated for the materials prepared at $0^{\circ} \mathrm{C}, 20^{\circ} \mathrm{C}$ and $50^{\circ} \mathrm{C}$ and further calcined at $300^{\circ} \mathrm{C}$, respectively.

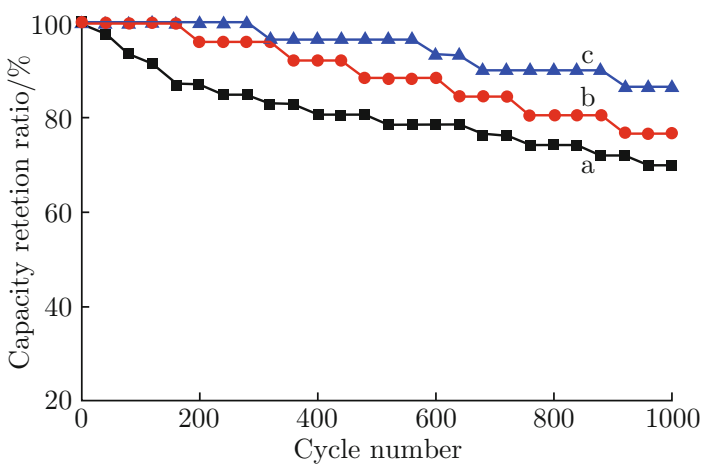

Fig. 6 Cycle life of as-prepared $\mathrm{NiO}$ electrode at a discharge current of $1 \mathrm{~A} / \mathrm{g}$ and $\mathrm{a}, \mathrm{b}, \mathrm{c}$ stands for the sample whose precursor synthesized at $0^{\circ} \mathrm{C}, 20^{\circ} \mathrm{C}$ and $50^{\circ} \mathrm{C}$, respectively.

To further investigate the influence of such nanostructure on electrolyte diffusion, EIS was conducted on the prepared $\mathrm{NiO}$. Figure $5(\mathrm{C})$ shows the Nyquist plots of the prepared $\mathrm{NiO}$ at the potential of $0.1 \mathrm{~V}$ with a frequency range from $10^{5}$ to $0.01 \mathrm{~Hz}$ in $6 \mathrm{M}$ $\mathrm{KOH}$. The Nyquist plots (Fig. 5(C)) show well-defined semicircles over the high frequency range, followed by straight sloped line in the low-frequency region for both samples. The diameter of the semicircle corresponds to the interfacial charge-transfer resistance $\left(R_{\mathrm{ct}}\right)$, which usually represents the resistance of electrochemical reactions on the electrode and is called the Faraday resistance, and the straight line is ascribed to the diffusive resistance (Warburg impendence, $W$ ) of electrolyte in electrode pores and the proton diffusion in host materials. As shown in Fig. 5(C), the nanoflake-shaped $\mathrm{NiO}$ exhibits a smaller semicircle than the other two at the high-frequency region, implies that the nanoflake has the lowest charge-transfer resistance, which may due to its higher crystallinity, and good hydrophilicity. However, the nanoflower-shaped $\mathrm{NiO}$ has a lowest slope, implying that the ion diffusion or transport is the most difficult in it. This can be explained by their hydrophilicity, the specimen formed at $50^{\circ} \mathrm{C}$ has a worse hydrophilicity than that of formed at $0^{\circ} \mathrm{C}$ and $20^{\circ} \mathrm{C}$. And the hydrophilicity of electrode materials will affect the diffusion of electrolyte in electrode materials. Furthermore, as shown in Fig. 5(D), the flower-liked $\mathrm{NiO}$ sphere has a worst rata capacity, while the $\mathrm{NiO}$ nanofakelets have best rate capacity.

Since long cycle life is very important to the supercapacitor, the charge/discharge cycles test was employed to examine the service life of the obtained different $\mathrm{NiO}$. Figure 6 shows the capacitance loss of the different $\mathrm{NiO}$ based electrodes with 1000 cycles. With the increasing of cycle number, the discharge capacitance for all the different $\mathrm{NiO}$ based electrodes is decrease gradually, and after 1000 cycles, for the $\mathrm{NiO}$ whose precursors was synthesized at $50^{\circ} \mathrm{C}$ retain $90 \%$ of its initial capacity, while the capacity-keeping rate of the $\mathrm{NiO}$ whose precursors was synthesized at $0^{\circ} \mathrm{C}$ is only $70 \%$. This indicated that the $\mathrm{NiO}$ has a high degree of crystallinity, suitable pore size distribution and little bigger particles size is more stable during the long charge and discharge processes.

\section{Conclusion}

A simple and effective ammonia precipitation method has been put forward to build different microstructured $\mathrm{NiO}$ by just adjusting the reaction temperature. It is found that the precipitation temperature has a great influence on the microstructure, hydrophilicity and electrochemical performance of products. Nanoflower liked $\mathrm{NiO}$ sphere could obtain at $0^{\circ} \mathrm{C}$, while, $\mathrm{NiO}$ nanoflakes are formed at $20^{\circ} \mathrm{C}$. The electrochemical results indicated that the nanoflower liked $\mathrm{NiO}$ has a highest specific capacity of $1538 \mathrm{~F} / \mathrm{g}$ at a current density of 0.4 $\mathrm{A} / \mathrm{g}$, which is closed to the highest capacity of $1609 \mathrm{~F} / \mathrm{g}$ reported by literatures so far [20], but its capacity obviously decreased with the increasing of current density. What's more, although the specific capacity of $\mathrm{NiO}$ nanoflakes is not very high, its rate capacity is excellent. All of these suggested that the preparation approach and microstructure of materials has a significantly impact on their electrochemical performance. Hence, to realize the full controlled synthesis of nanomaterials is very important for their applications. According to our experimental results, not only large surface area and porous structure but good hydrophilicity has a significantly impact on the electrochemical performance of $\mathrm{NiO}$. Hence, further improvement of this experiment should be focused on enhancing the hydrophilicity of $\mathrm{NiO}$ whose precursor formed at $0^{\circ} \mathrm{C}$, introduce surfactant into the reaction solution may be a good choice $[21]$. 


\section{Acknowledgements}

This work is financially supported by the National Natural Science Foundation of China (21063014 and 21163021), Fundamental Research Funds for the Central Universities (XDJK2013B031) and the Natural Science Foundation of Chongqing (cstc2013jcyjA0396).

\section{References}

[1] B. J. Melde and B. J. Johnson, "Mesoporous materials in sensing: morphology and functionality at the meso-interface", Anal. Bioanal. Chem. 398(4), 1565-73 (2010). http://dx.doi.org/10.1007/ s00216-010-3688-6

[2] Q. Li, L.-S. Wang, B.-Y. Hu, C. Yang, L. Zhou and L. Zhang, "Preparation and characterization of $\mathrm{NiO}$ nanoparticles through calcination of malate gel", Mater. Lett. 61(8-9), 1615-1618 (2007). http://dx. doi.org/10.1016/j.matlet.2006.07.113

[3] Z.-H. Liang, Y.-J. Zhu and X.-L. Hu, " $\beta$-Nickel hydroxide nanosheets and their thermal decomposition to nickel oxide nanosheets", J. Phys. Chem. Lett. B 108(11), 3488-3491 (2004). http://dx.doi.org/10. 1021/jp037513n

[4] S. A. Needham, G. X. Wang and H. K. Liu, "Synthesis of $\mathrm{NiO}$ nanotubes for use as negative electrodes in lithium ion batteries", J. Power Sources 159(1), 254-257 (2006). http://dx.doi.org/10.1016/ j.jpowsour. 2006.04.025

[5] C. Xu, K. Hong, S. Liu, G. Wang and X. Zhao, "A novel wet chemical route to $\mathrm{NiO}$ nanowires", J. Cryst. Growth 255(3-4), 308-312 (2003). http://dx. doi.org/10.1016/s0022-0248(03)01246-6

[6] K. Matsui, B. K. Pradhan, T. Kyotani and A. Tomita, "Formation of nickel oxide nanoribbons in the cavity of carbon nanotubes", J. Phys. Chem. Lett. B 105(24), 5682-5688 (2001). http://dx.doi.org/10. 1021/jp010496m

[7] X. Wang, L. Yu, P. Hu and F. Yuan, "Synthesis of single-crystalline hollow octahedral NiO", Crystal Growth \& Design 7(12), 2415-2418 (2007). http:// dx.doi.org/10.1021/cg060957z

[8] B. Varghese, M. Reddy, Z. Yanwu, C. S. Lit, T. C. Hoong, G. Subba Rao, B. Chowdari, A. T. S. Wee, C. T. Lim and C.-H. Sow, "Fabrication of $\mathrm{NiO}$ nanowall electrodes for high performance lithium ion battery", Chem. Mater. 20(10), 3360-3367 (2008). http://dx. doi.org/10.1021/cm703512k

[9] W. Zhou, M. Yao, L. Guo, Y. Li, J. Li and S. Yang, "Hydrazine-linked convergent self-assembly of sophisticated concave polyhedrons of beta- $\mathrm{Ni}(\mathrm{OH})_{2}$ and $\mathrm{NiO}$ from nanoplate building blocks", J. Am. Chem. Soc. 131(8), 2959-2964 (2009). http://dx.doi.org/ 10.1021/ja808784s

[10] J. Liu, S. Du, L. Wei, H. Liu, Y. Tian and Y. Chen, "Template-free synthesis of $\mathrm{NiO}$ hollow microspheres covered with nanoflakes", Mater. Lett. 60(29), 36013604 (2006). http://dx.doi.org/10.1016/j.matlet. 2006.03 .068

[11] M.-S. Wu and H.-H. Hsieh, "Nickel oxide/hydroxide nanoplatelets synthesized by chemical precipitation for electrochemical capacitors", Electrochimica Acta 53(8), 3427-3435 (2008). http://dx.doi.org/10. 1016/j.electacta.2007.12.005

[12] Q. Yang, J. Sha, X. Ma and D. Yang, "Synthesis of NiO nanowires by a sol-gel process", Mater. Lett. 59(1415), 1967-1970 (2005). http://dx.doi.org/10.1016/ j.matlet.2005.02.037

[13] P. Palanisamy and A. M. Raichur, "Synthesis of spherical $\mathrm{NiO}$ nanoparticles through a novel biosurfactant mediated emulsion technique", Mater. Sci. Eng. C 29(1), 199-204 (2009). http://dx.doi.org/10.1016/ j.msec. 2008.06.008

[14] E. R. Beach, K. Shqau, S. E. Brown, S. J. Rozeveld and P. A. Morris, "Solvothermal synthesis of crystalline nickel oxide nanoparticles", Mater. Chem. \& Phys. 115(1), 371-377 (2009). http://dx.doi.org/10. 1016/j .matchemphys . 2008.12.018

[15] Hua Jiao, "Urchin-like NiO Superstructures Prepared by Simple Thermal Decomposition Process", NanoMicro Lett. 3(3), 166-170 (2011). http://dx.doi.org/ 10.3786/nml .v3i3.p166-170

[16] J. W. Lang, L. B. Kong, W. J. Wu, Y. C. Luo and L. Kang, "Facile approach to prepare loose-packed $\mathrm{NiO}$ nano-flakes materials for supercapacitors", Chem. Commun. 35, 4213-4215 (2008). http://dx.doi.org/ 10.1039/B800264A

[17] J. Huang, Y. Wu, C. Gu, M. Zhai, K. Yu, M. Yang and J. Liu, "Large-scale synthesis of flowerlike $\mathrm{ZnO}$ nanostructure by a simple chemical solution route and its gas-sensing property", Sens. Act. B: Chem. 146(1), 206-212 (2010). http://dx.doi.org/10.1016/j.snb. 2010.02 .052

[18] L. S. Zhong, J. S. Hu, H. P. Liang, A. M. Cao, W. G. Song and L. J. Wan, "Self-Assembled 3D flowerlike iron oxide nanostructures and their application in water treatment", Adv. Mater. 18(18), 2426-2431 (2006). http://dx.doi.org/10.1002/adma. 200600504

[19] S. Zeng, K. Tang, T. Li, Z. Liang, D. Wang, Y. Wang, Y. Qi and W. Zhou, "Facile route for the fabrication of porous hematite nanoflowers: its synthesis, growth mechanism, application in the lithium ion battery, and magnetic and photocatalytic properties", J. Phys. Chem. Lett. C 112(13), 4836-4843 (2008). http://dx. doi.org/10.1021/jp0768773

[20] H. Pang, B. Zhang, J. Du, J. Chen, J. Zhang and S. $\mathrm{Li}$, "Porous nickel oxide nanospindles with huge specific capacitance and long-life cycle", RSC Adv. 2 (6), 2257-2261 (2012).

[21] B. Chang, X. Zhang, J. Guo, Y. Sun, H. Tang, Q. Ren and W. Yang, "General one-pot strategy to prepare multifunctional nanocomposites with hydrophilic colloidal nanoparticles core/mesoporous silica shell structure", Journal of colloid and interface science. 377 (1), 64-75 (2012). 